DOI: 10.12957/demetra.2016.21085

\title{
Avaliação da conformidade de capacidade volumétrica de caçarolas e caldeirões frente às especificações do fabricante e a legislação brasileira
}

\section{Assessment of conformity of volumetric capacity of casseroles and cauldrons to manufacturer's specifications and the Brazilian legislation}

Valdirene Francisca Neves dos Santos'

Bianca Pinho Santos'

Ana Carolina K. Miguez

Ornella Antonini ${ }^{1}$

Maria Cristina de Almeida Gaspar'

1 Universidade Paulista, Instituto de Ciências da Saúde. São Paulo-SP, Brasil.

Correspondência / Correspondence Valdirene Francisca Neves dos Santos E-mail:val_usp@hotmail.com

\section{Resumo}

As caçarolas e caldeirões de alumínios são utensílios indispensáveis em cozinhas domésticas e Unidades de Alimentação e Nutrição (UAN). Conhecer sua capacidade volumétrica possui relevância na prática das UANs, uma vez que conduz ao controle mais efetivo quanto à administração e porcionamento dos alimentos, reduzindo as chances de desperdícios ou otimizando o espaço de seu armazenamento. Assim, planejou-se o presente estudo a fim de avaliar se a capacidade volumétrica de caçarolas e caldeirões, descrita pelos fabricantes, encontra-se de acordo com os valores reais analisados e em concordância com a legislação. Foram estudados 12 tipos de caçarolas e nove tipos de caldeirões. As avaliações foram feitas em triplicatas. Análise de variância e o teste t de Student foram utilizados para as comparações dos valores descritos pelos Fabricantes versus Medida Real encontrada. Os valores foram comparados com os descritos pela legislação brasileira em vigor. Os valores da capacidade volumétrica anunciados pelos fabricantes, quando comparados com os avaliados, não apresentaram diferenças estatisticamente significantes. Todavia, salienta-se a expressiva variação volumétrica permitida pela legislação e a falta de clareza na exatidão da capacidade volumétrica de caçarolas e caldeirões da linha industrial, utilizadas nas UANs. Observou-se não conformidade com a legislação quanto às informações que devem constar de forma permanente no corpo das caçarolas e caldeirões em 72\% dos analisados. Conclui-se que são necessários cuidados na utilização desses utensílios, durante a elaboração de preparações culinárias. Sugere-se reformulação da norma 
brasileira sobre a capacidade volumétrica desses produtos, considerando variações volumétricas não superiores a $20 \%$.

Palavras-chave: Serviços de Alimentação. Utensílios de Alimentação e Culinária. Legislação em Ciência e Tecnologia. Pesos e Medidas. Normas Técnicas.

\section{Abstract}

Aluminum casseroles and cauldrons are indispensable tools in domestic kitchens and food and nutrition units (FNU). Knowledge about their volumetric capacity has relevance in practice of FNUs, since it leads to more effective control of the management and portioning of food, thus reducing the chances of waste or optimizing food storage space. Thus, this study was planned to assess if the volumetric capacity of casseroles and cauldrons, described by the manufacturers, reflects the actual values analyzed and if they are in accordance with the current legislation. Were studied twelve kinds of casseroles and nine kinds of cauldrons. The evaluations were made in three repetitions. Analysis of variance and Student's t-test were used for comparisons of the values described by the manufacturers versus the actual measurement found. The values were compared with those described by the Brazilian Legislation in force. The volumetric capacity values reported by the manufacturers, when compared with the measured ones, showed no statistically significant difference. However, there was significant volumetric variation permitted by the legislation and the lack of clarity on the accuracy of volumetric capacity of industrial-line casseroles and cauldrons used in FNUs. There was non-compliance with the legislation regarding the information to be included on a permanent basis in the body of the pans and cauldrons on $72 \%$ of the analyzed utensils. It is concluded that care is needed in using these tools during the preparation of food. Reformulation is suggested of the Brazilian standard on the volumetric capacity of these items, considering volume variation that does not exceed $20 \%$.

Key words: Food Services. Cooking and Eating Utensils. Science and Technology Regislation. Weights and Measures. Technical Standards. 


\section{Introdução}

A influência portuguesa, na culinária brasileira e no hábito da utilização de panelas metálicas, é observada desde a colonização. ${ }^{1}$

A participação de ampla variedade de materiais utilizados pelo homem na confecção de panelas é traço marcante no território brasileiro, onde se observa panelas para comercialização de: vidro, bronze, cerâmica, cobre, esmaltadas, ferro, aço inoxidável, pedra-sabão, barro, alumínio com polietrafluoretileno (teflon), alumínio com aço inoxidável, alumínio fundido ou laminado. ${ }^{2,3}$

A partir do século XX, as panelas foram predominantemente produzidas em alumínio e aço inoxidável, isso aconteceu devido à facilidade do manuseio e menor custo., ${ }^{2,4}$

É sabido que, na atualidade, outros fatores atrelados aos citados favorecem o sucesso nas vendas das panelas de alumínio, como maior resistência à corrosão e a excelência na condutividade térmica, proporcionando condução homogênea de calor que favorece o cozimento uniforme do alimento.

Quanto aos requisitos técnicos envolvidos na fabricação das panelas metálicas, o corpo do utensílio pode ser fabricado com os seguintes materiais: alumínio laminado, alumínio fundido ou aço inoxidável laminado, aço laminado para estampagem média ou profunda, ferro fundido e cobre. ${ }^{5}$

Na produção das panelas de alumínio fundido, também conhecida como panela de alumínio artesanal, são utilizados materiais reciclados, provindos de "ferro velho", que variam de uma placa de carro velha (sucata) a material de construção. Esse alumínio é derretido em alta temperatura, para que ocorra a fabricação da panela. ${ }^{6}$

Por outro lado, na fabricação da panela de alumínio laminado utiliza-se uma máquina conhecida como "torno de repuxo", onde um disco de alumínio laminado é repuxado, para a formação da panela de alumínio.

Atualmente, as caçarolas e caldeirões de alumínio laminado são amplamente utilizados e foram classificados pelos fabricantes em linha doméstica e hoteleira, esta última também conhecida como linha industrial.

As caçarolas de alumínio são panelas com bordas altas, porém mais larga do que alta, com cabo e tampa de variados tamanhos. ${ }^{7}$ Enquanto os caldeirões de alumínio são panelas grandes, mais altas que largas, comumente dotadas de alça. ${ }^{8}$

As caçarolas e caldeirões de alumínios são considerados utensílios básicos em cozinhas domésticas e Unidades de Alimentação e Nutrição (UAN). ${ }^{9,10}$

Visando à garantia da segurança dos consumidores, a legislação brasileira formulou diretrizes para a avaliação de conformidade desses utensílios na linha doméstica. ${ }^{5,11}$ 
A capacidade volumétrica consiste no volume total contido pelo corpo dessas panelas, até o seu limite antes do transbordamento, e somente poderá ser atingida se o utensílio estiver em condições adequadas. ${ }^{12}$

As caçarolas e caldeirões de alumínio laminado encontrados no mercado para comercialização diferem entre si devido à designação. Entende-se por designação o número inserido no corpo da panela, que representa a capacidade volumétrica do utensílio. ${ }^{12} \mathrm{Na}$ linha doméstica são encontradas para vendas as designações: $8,10,12,14,16,18,20,22,24,26,28,30,32,34$. Designações acima de 34 compõem a linha hoteleira, também conhecida como linha industrial.

Ao analisar a linha industrial das caçarolas e caldeirões de alumínio, disponíveis para a venda, são encontradas as seguintes designações $\left(\mathrm{n}^{\mathrm{o}}\right)$ : $36,38,40,45,50,55,60$, 70. Sendo que os valores da capacidade volumétrica variam de 17 litros para a designação 36 a 125 litros para a 70 .

Em 2012, foram estabelecidos requisitos técnicos pela legislação, que determinam que durante a confecção das caçarolas e caldeirões de alumínio os fabricantes marquem de maneira clara e permanente o nome da empresa, designação e diâmetro nominal, na parte inferior desses utensílios, a fim de garantir o rastreamento. ${ }^{5}$

A Associação Brasileira de Normas Técnicas (ABNT), através de uma Comissão de Estudos, em 2008, formulou a Norma Brasileira - NBR: 14630, que regulamenta os utensílios domésticos metálicos para uso em forno e fogão. ${ }^{12}$

Diversas modalidades de atendimento influenciam na escolha e no dimensionamento desses utensílios nas UANs, como: padrão de cardápios, número de refeições, política de compras, efetivo da mão de obra, rentabilidade do investimento, sistema de distribuição. ${ }^{13}$

Conhecimento sobre a capacidade volumétrica de caçarolas e caldeirões de alumínio possui relevância na prática de uma cozinha doméstica ou UAN, uma vez que esse esclarecimento conduz a um controle mais efetivo quanto à administração e porcionamento dos alimentos preparados nesses utensílios, a fim de se evitar o desperdício de alimentos e melhor otimização quanto ao espaço de armazenagem.

Todavia, ainda são incipientes na literatura estudos que avaliem se os valores da capacidade volumétrica de caçarolas e caldeirões, descritos pelos fabricantes, encontram-se em concordância e conformidade com a legislação vigente..$^{5,11,12}$

Assim, planejou-se este estudo com a finalidade de avaliar se a capacidade volumétrica de caçarolas e de caldeirões de alumínio, descrita pelos fabricantes, está compatível com os valores reais analisados e em concordância com a legislação. 


\section{Métodos}

Trata-se de um estudo transversal, analítico e prospectivo. ${ }^{14} \mathrm{O}$ estudo foi realizado na cidade de São Paulo, durante o período de outubro de 2014 a agosto de 2015.

As amostras foram adquiridas por conveniência e foram obtidas pelos pesquisadores em lojas que comercializam equipamentos e utensílios para cozinhas domésticas e industriais.

\section{Designação das caçarolas e caldeirões investigados}

Foi possível a realização do estudo em 12 designações de caçarolas de alumínio e nove de caldeirões de alumínio. As avaliações foram realizadas em triplicatas, totalizando 36 caçarolas e 27 caldeirões de duas marcas (marca A e B).

As designações das caçarolas investigadas foram as de números 16, 18, 20, 22, 24, 26, 28, 30, 32, 34, 36 e 38, sendo três caçarolas de cada designação. Enquanto as designações dos caldeirões avaliados foram as de números $16,26,28,30,32,34,36,38$ e 40, sendo três caldeirões de cada designação.

Quinze caçarolas analisadas pertenciam à marca $\mathrm{A}$ e 21 à $\mathrm{B}$. No tocante aos caldeirões, nove à $\mathrm{A}$ e 18 à $\mathrm{B}$.

\section{Avaliação da capacidade volumétrica real}

O projeto foi realizado no laboratório de Nutrição da Universidade Paulista, São Paulo, Brasil.

Todas as caçarolas e caldeirões eram de alumínio laminado, sem revestimento interno, novas e isenta de defeitos, a fim de favorecer a acurácia dos resultados.

A capacidade volumétrica das caçarolas e caldeirões de alumínio foi definida no parágrafo 3.1 da Norma Brasileira: 14630, da Associação Brasileira de Normas Técnicas (2008), como o volume total contido no corpo do utensílio até o seu limite antes do transbordamento. ${ }^{12}$

Posteriormente, realizou-se ligações telefônicas para as empresas de fabricação de caçarolas e caldeirões de alumínio a fim de se conhecer a metodologia utilizada na determinação da capacidade volumétrica. Duas empresas envolvidas alegam seguir as normas recomendadas pela Norma Brasileira da ABNT (2008)..$^{12}$

Neste estudo, a título de comparação, essas especificações, segundo a legislação, foram seguidas, para a determinação dos valores correspondentes à medida real das caçarolas e caldeirões de alumínio. 
Utilizou-se na aferição da capacidade volumétrica dos utensílios proveta com água, com capacidade máxima de 2.000 mililitros.

Para a leitura da capacidade volumétrica, cada utensílio foi colocado em superfície plana, com o apoio da proveta, e o corpo das panelas foi preenchido com água até a altura do ponto limite do transbordamento. ${ }^{12}$

A leitura dos valores encontrados durante a aferição no laboratório foi descrita, no presente estudo, como Medida Real. As aferições foram realizadas em triplicatas para cada caçarola e caldeirão investigados.

Os valores da média encontrados das medições das caçarolas e caldeirões foram inseridos em planilhas do Microsoft Excel e comparados com os valores especificados pelo fabricante nos rótulos dos utensílios.

Posteriormente, os resultados, foram analisados segundo a legislação brasileira vigente à época da avaliação dos dados: Norma Brasileira - NBR: 14630, da Associação Brasileira de Normas Técnicas (2008), portaria no 398, de 31 de julho de 2012, do Instituto Nacional de Metrologia, Qualidade e Tecnologia (InMetro) e portaria no 408, de 21 de agosto de 2015, do InMetro, para a verificação da concordância entre os valores encontrados com os descritos pelos fabricantes. ${ }^{5,11,12}$

As análises dos dados foram realizadas utilizando-se o Software Stata, versão 11.0. (Stata Corp. College Station, Estados Unidos). Em todos os testes, fixou-se nível de significância de $5 \%$ (p<0,05) para a rejeição da hipótese de nulidade.

Análise de variância e o teste t de Student foram usados para as comparações entre duas medidas, isto é, a obtenção da capacidade volumétrica informada pelo Fabricante versus Medida Real.

O estudo foi aprovado pelo Comitê de Ética dessa instituição, CAAE: 36422814.2.0000.5512, e número do parecer: 827.338, de 9 de outubro de 2014.

\section{Resultados}

Das 36 caçarolas de alumínio investigadas, $42 \%$ correspondiam à marca $\mathrm{A}$ e $58 \%$, à B, enquanto que dos 27 caldeirões, 33\% à A e 67\% à B. Observa-se que os valores da capacidade volumétrica encontrados da Medida Real, quando comparados aos valores anunciados pelos fabricantes, não apresentam diferenças estatisticamente significantes. Esses valores estão descritos nas tabelas 1 e 2. 
Tabela 1. Descrição da designação e capacidade volumétrica de caçarolas e caldeirões de alumínio descritas pelos fabricantes, valores médios da medição real de acordo com as diferentes marcas avaliadas. São Paulo, 2015.

\begin{tabular}{|c|c|c|c|}
\hline $\begin{array}{c}\text { CAÇAROLAS } \\
\text { DESIGNAÇÕES }\end{array}$ & MARCA & $\begin{array}{c}\text { CAPACIDADE } \\
\text { VOLUMÉTRICA } \\
\text { ESPECIFICAÇÕES DO } \\
\text { FABRICANTE LT }\end{array}$ & $\begin{array}{l}\text { VALORES MÉDIOS } \\
\text { MEDIÇÃO REAL } \\
(\mathrm{N}=3)\end{array}$ \\
\hline № 16 & $\mathrm{~A}$ & 1,6 & 1,63 \\
\hline № 18 & A & 2,2 & 2,29 \\
\hline № 20 & A & 3,1 & 3,2 \\
\hline № 22 & $\mathrm{~A}$ & 4,1 & 4 \\
\hline № 24 & A & 5,6 & 5,79 \\
\hline № 26 & B & 6,8 & 6,19 \\
\hline № 28 & B & 8,3 & 7,9 \\
\hline № 30 & B & 9,5 & 10,4 \\
\hline № 32 & B & 12 & 11,7 \\
\hline № 34 & B & 14,5 & 14,04 \\
\hline № 36 & B & 17 & 16,7 \\
\hline № 38 & B & 20 & 19,1 \\
\hline $\begin{array}{c}\text { CALDEIRÕES } \\
\text { DESIGNAÇÕES }\end{array}$ & MARCA & & \\
\hline № 16 & A & 3,2 & 3,02 \\
\hline № 26 & A & 12,7 & 12,3 \\
\hline № 28 & B & 15,3 & 14,5 \\
\hline № 30 & B & 19 & 18,2 \\
\hline № 32 & B & 22,5 & 22,2 \\
\hline № 34 & B & 27 & 26,9 \\
\hline № 36 & B & 32,5 & 32,2 \\
\hline № 38 & B & 38 & 38,2 \\
\hline № 40 & A & 45 & 44,9 \\
\hline
\end{tabular}


Tabela 2. Comparação da capacidade volumétrica de caçarolas e caldeirões descrita nos rótulos dos utensílios pelos fabricantes com as medidas reais. São Paulo, 2015.

\begin{tabular}{lccc}
\hline Utensílios & $\begin{array}{c}\text { Fabricante } \\
\text { Média }(\mathrm{DP})\end{array}$ & $\begin{array}{c}\text { Medida Real } \\
\text { Média (DP) }\end{array}$ & $\mathrm{p}$ \\
\hline Caçarola $(\mathrm{n}=36)$ & $8,73(3,03)$ & $8,58(5,81)$ & 0,992 \\
\hline Caldeirão $(\mathrm{n}=27)$ & $23,91(13,14)$ & $23,60(13,34)$ & 0,979 \\
\hline
\end{tabular}

Teste $T$ de Student ao nível de $5 \%$ de probabilidade de erro.

Analisando os valores preconizados pela NBR: 14630, da ABNT (2008), ${ }^{12}$ observa-se que $94 \%$ das caçarolas pertencentes à linha doméstica avaliadas encontravam-se em conformidade. E $100 \%$ dos caldeirões da linha doméstica correspondiam aos padrões esperados de conformidade volumétrica. Esses dados foram descritos na tabela 3. 
Tabela 3. Avaliação comparativa entre valores da capacidade volumétrica de caçarolas e caldeirões de alumínio descritos pelos fabricantes e sua conformidade com os limites de variação permitidos pela Norma Brasileira 14630 da Associação Brasileira de Normas Técnicas (2008). São Paulo, 2015.

\begin{tabular}{|c|c|c|c|}
\hline Designação $^{1}$ & $\begin{array}{c}\text { Capacidade volumétrica } \\
\text { Segundo a ABNT NBR } \\
\text { 14630:2008 } \\
\text { L }\end{array}$ & $\begin{array}{c}\text { Capacidade volumétrica } \\
\text { de acordo com } \\
\text { os fabricantes }\end{array}$ & Conformidade \\
\hline \multicolumn{4}{|c|}{ Caçarolas } \\
\hline № 16 & $1,20-1,80$ & 1,60 & Conforme \\
\hline № 18 & $1,50-2,30$ & 2,20 & Conforme \\
\hline № 20 & $2,10-3,3$ & 3,10 & Conforme \\
\hline № 22 & $2,90-4,30$ & 4,10 & Conforme \\
\hline № 24 & $3,50-5,40$ & 5,60 & Não Conforme \\
\hline № 26 & $5,00-7,00$ & 6,30 & Conforme \\
\hline № 28 & $6,50-8,50$ & 8,30 & Conforme \\
\hline № 30 & $8,50-11,50$ & 9,50 & Conforme \\
\hline № 32 & $10,50-13,50$ & 12,0 & Conforme \\
\hline № 34 & $13,0-17,0$ & 14,50 & Conforme \\
\hline № 36 & Não especificado & 17,0 & $*$ \\
\hline $\mathrm{N}^{\circ} 38$ & Não especificado & 20,0 & $*$ \\
\hline \multicolumn{4}{|c|}{ Caldeirões } \\
\hline № 16 & $>1,80$ & 3,20 & Conforme \\
\hline № 26 & $>7,00$ & 8,30 & Conforme \\
\hline № 28 & $>8,50$ & 10,30 & Conforme \\
\hline № 30 & $>11,50$ & 12,70 & Conforme \\
\hline № 32 & $>13,5$ & 15,30 & Conforme \\
\hline № 34 & $>17,0$ & 19,00 & Conforme \\
\hline № 36 & Não especificado & 22,50 & $*$ \\
\hline № 38 & Não especificado & 27,00 & $*$ \\
\hline № 40 & Não especificado & 45,00 & $*$ \\
\hline
\end{tabular}

*Designação da linha industrial não especificada pela ABNT NBR 14630:2008, não sendo possível a avaliação da conformidade. 
No presente estudo não foi possível a realização da avaliação comparativa quanto à conformidade dos utensílios da linha industrial (designações n⿳0 36, 38 de caçarolas e no $36,38,40$ dos caldeirões), uma vez que a NBR: 14630, da ABNT (2008), ${ }^{12}$ não especifica com clareza os valores quanto à variação aceitável para a capacidade volumétrica das caçarolas e caldeirões de alumínio pertencentes a essa linha.

Ao considerar a portaria no 398, de 31 de julho de 2012, do Instituto Nacional de Metrologia, Qualidade e Tecnologia, salienta-se que $72 \%$ das caçarolas e caldeirões de alumínio encontravam-se em não conformidade, devido à ausência do nome da empresa, designação e diâmetro nominal, que deveriam ser descritos no corpo do utensílio de forma permanente a fim de garantir o rastreamento do utensílio e maior garantia de segurança ao consumidor. ${ }^{5}$

No entanto, a portaria no 408, de 21 de agosto de 2015, do Instituto Nacional de Metrologia, Qualidade e Tecnologia, ${ }^{11}$ que regulamenta sobre a qualidade e requisitos de avaliação da conformidade para panelas metálicas da linha doméstica, dispõe que os fabricantes de panelas metálicas possuem o prazo de até 13 de outubro de 2017 para se adequar a esses requisitos solicitados pela portaria no 398, de 31 de julho de 2012, do Instituto Nacional de Metrologia, Qualidade e Tecnologia. ${ }^{5}$

Todas as variações permitidas quanto à capacidade volumétrica para os diversos tipos de caçarolas e caldeirões de alumínio, preconizadas pela NBR: 14630, da Associação Brasileira de Normas Técnicas (2008), foram descritas no quadro 1, no qual se evidencia que para os caldeirões foram designados somente valores de limite inferiores quanto à capacidade volumétrica de cada designação da linha doméstica. E a não existência de informações precisas sobre os valores limítrofes para a capacidade volumétrica de caçarolas e caldeirões de alumínio pertencentes à linha industrial. 
Quadro 1. Designação e capacidade volumétrica de caçarolas e caldeirões para uso em forno e fogão de acordo com normas preconizadas pela Norma Brasileira 14630 da Associação Brasileira de Normas Técnicas (2008). São Paulo, 2015.

\begin{tabular}{|c|c|c|}
\hline \multirow{2}{*}{ Designação $^{1}$} & \multicolumn{2}{|c|}{ Capacidade volumétrica $(\mathrm{cv})$} \\
\cline { 2 - 3 } & Caçarola & Caldeirão \\
\hline 8 & $400 \leq \mathrm{cv} \leq 600$ & $\mathrm{cv}>600$ \\
\hline 10 & $500 \leq \mathrm{cv} \leq 700$ & $\mathrm{cv}>700$ \\
\hline 12 & $700 \leq \mathrm{cv} \leq 900$ & $\mathrm{cv}>900$ \\
\hline 14 & $1000 \leq \mathrm{cv} \leq 1200$ & $\mathrm{cv}>1200$ \\
\hline 16 & $1200 \leq \mathrm{cv} \leq 1800$ & $\mathrm{cv}>2300$ \\
\hline 18 & $1500 \leq \mathrm{cv} \leq 2300$ & $\mathrm{cv}>3300$ \\
\hline 20 & $2100 \leq \mathrm{cv} \leq 3300$ & $\mathrm{cv}>4300$ \\
\hline 22 & $2900 \leq \mathrm{cv} \leq 4300$ & $\mathrm{cv}>5400$ \\
\hline 24 & $3500 \leq \mathrm{cv} \leq 5400$ & $\mathrm{cv}>7000$ \\
\hline 26 & $5000 \leq \mathrm{cv} \leq 7000$ & $\mathrm{cv}>8500$ \\
\hline 28 & $6500 \leq \mathrm{cv} \leq 8500$ & $\mathrm{cv}>11500$ \\
\hline 30 & $8500 \leq \mathrm{cv} \leq 11500$ & $\mathrm{cv}>13500$ \\
\hline 32 & $10500 \leq \mathrm{cv} \leq 13500$ & 17000 \\
\hline 34 & $13000 \leq \mathrm{cv} \leq 17000$ & c \\
\hline Designação que não se enquadrar nesta tabela deve ser classificada de acordo com o \\
\hline
\end{tabular}

\section{Discussão}

No presente estudo não foram encontrados na literatura nacional e internacional outras pesquisas que tenham avaliado se a capacidade volumétrica de caçarolas e de caldeirões de alumínio, descrita pelos fabricantes, encontra-se compatível com os valores reais analisados e em concordância com a legislação.

Ressalta-se, dessa maneira, a importância do assunto abordado e as limitações do presente estudo em não conseguir resultados de outras pesquisas para maior abrangência da discussão sobre este assunto. 
Ao se avaliar a concordância da conformidade da capacidade volumétrica entre os valores descritos pela NBR: 14630, da Associação Brasileira de Normas Técnicas (2008), com os valores informados pelos Fabricantes versus Medidas Reais, constatou-se que $94 \%$ das caçarolas e caldeirões da linha doméstica atendem ao padrão de conformidade. Os valores volumétricos das caçarolas e caldeirões analisados oscilaram entre $100 \mathrm{ml} \mathrm{e} 2.500 \mathrm{ml}$.

Todavia, apesar do alto índice de conformidade entre os valores descritos pelos Fabricantes versus Medidas Reais, quando comparados com os valores da NBR: 14630, da Associação Brasileira de Normas Técnicas (2008), nota-se uma expressiva variação volumétrica permitida, já que os valores percentuais das variantes volumétricas das diversas designações de caçarolas variam de $20 \%$ a 57\%, com variação percentual média de 40\%, deixando em evidência o quanto essa legislação permite uma grande variação volumétrica nesses utensílios. ${ }^{12}$

Observou-se a tendência da NBR: 14630, da Associação Brasileira de Normas Técnicas (2008), em conduzir o leitor a erros quanto ao conhecimento da capacidade volumétrica de caçarolas de alumínio, uma vez que algumas caçarolas se enquadram em mais de uma designação.

Esse fato pode ser demonstrado na aquisição de uma caçarola com capacidade volumétrica de $500 \mathrm{ml}$, que poderá se enquadrar na designação no 8 ou nํㅜ 10. O mesmo equívoco foi observado para as caçarolas com capacidade volumétrica de $2.100 \mathrm{ml}, 5.000 \mathrm{ml}, 6.500 \mathrm{ml}, 10.500 \mathrm{ml}, 13.000 \mathrm{ml}$, todas podendo se enquadrar em mais de uma designação, fato que poderá prejudicar o consumidor no momento da compra, devido à tendência ao maior custo na aquisição das designações maiores.

Salienta-se ainda a não existência de designação para as caçarolas com capacidade volumétrica $\geq 901 \mathrm{ml} \mathrm{e} \leq 999 \mathrm{ml}$.

Em relação aos caldeirões, observou-se que a NBR: 14630, da Associação Brasileira de Normas Técnicas (2008), determina somente limites inferiores de capacidade volumétrica. Sendo assim, o caldeirão da designação no 8, por exemplo, poderá variar de $601 \mathrm{ml}$ ao infinito. A mesma ideia é válida para as outras designações de caldeirões, da linha doméstica descrita. ${ }^{12}$

Ressalta-se a importância dessa discussão na medida em que a linha industrial envolve caçarolas e caldeirões de alumínio com capacidade volumétrica superior à da linha doméstica, sendo que os equívocos volumétricos representam maiores perdas. Logo, a variação volumétrica deveria ser melhor controlada, a fim de se evitar na UAN perda financeira por desperdício de alimentos, ou menor otimização do tempo de preparo devido à falta de clareza quanto à designação do utensílio.

Um exemplo a ser citado é quando se acredita que a caçarola e o caldeirão de alumínio tenham determinada capacidade volumétrica, e ao produzir uma comida, o alimento se extravasa por desconhecimento da designação do utensílio, o que acaba por onerar o custo do cardápio por conta do inconveniente da perda inesperada. Ou, por outro lado, quando a capacidade volumétrica 
for maior do que o descrito na designação do utensílio e, inesperadamente, acaba por otimizar o espaço de armazenagem do alimento durante a preparação, que poderia ter oferecido maior economia quanto ao tempo, se fosse produzida somente uma vez, se conhecida a capacidade volumétrica real. ${ }^{15}$

Outro inconveniente observado na NBR: 14630, da Associação Brasileira de Normas Técnicas (2008), é a dificuldade de acesso a essas informações. Para obtê-las, deve-se pagar por elas, assim parte da população é privada da aquisição de conhecimento sobre as normas estabelecidas que devem ser seguidas pelos fabricantes. ${ }^{12}$

Considerou-se também a NBR: 14630, da Associação Brasileira de Normas Técnicas (2008), de difícil entendimento e apresentando ambiguidades de expressões, uma vez que escreveram no rodapé da tabela 1:"Designação que não se enquadrar nesta tabela deve ser classificada de acordo com o número inteiro da designação imediatamente inferior."

De acordo com a portaria no 398, de 31 de julho de 2012, do Instituto Nacional de Metrologia, Qualidade e Tecnologia, devem constar de modo permanente no corpo do utensílio, a designação, nome da empresa e diâmetro nominal. ${ }^{5}$ No entanto, no presente estudo a maioria dos fabricantes (72\%) utilizaram papel adesivo, contendo o nome do fornecedor, a capacidade volumétrica e a identificação para o rastreamento. Todavia, uma vez que a população leiga não possui o entendimento quanto à importância de se guardar os dados sobre o fabricante, o papel adesivo costuma ser desprezado e, dessa maneira, perde-se a oportunidade de um possível rastreamento futuro.

Sendo assim, são impraticáveis, ao longo do tempo, a utilização desses utensílios com exatidão volumétrica, durante a elaboração de receitas culinárias, pois tais dados possivelmente serão perdidos, uma vez que muitas empresas ainda não apresentam essas informações de modo permanente no corpo do utensílio de acordo com o preconizado pela portaria no 398, do Inmetro de 2012. ${ }^{5}$ No entanto, vale salientar, que os fabricantes possuem respaldo para essa prática através da portaria no 408, de 21 de agosto de 2015, do Instituto Nacional de Metrologia, Qualidade e Tecnologia, que permite tolerância aos fabricantes para essa adequação da conformidade até meados de outubro de 2017.

O rastreamento do utensílio é de extrema importância, pois na possibilidade de um agravo à saúde, a identificação do lote de caçarola e caldeirões de alumínio factível de algum tipo de material tóxico pode ser identificado e retirado do mercado, bem como definir a responsabilidade de cada um dos intervenientes na produção. Permite, assim, uma intervenção rápida por parte das autoridades competentes.

O rastreamento favorece, também, o acompanhamento de empresas idôneas que asseguram adequação quanto ao diâmetro nominal (espessura do revestimento) a fim de que o consumidor 
não seja enganado quanto ao tempo de vida útil do utensílio, e a presença de dilatações no utensílio conforme o uso, que pode favorecer a formação de ondulações, que interfere na capacidade volumétrica total, práticas essas que podem ser realizadas por empresas não idôneas, que não obedecem ao diâmetro nominal determinado pela Norma regulamentadora e pela portaria $\mathrm{n}^{\mathrm{o}}$ 398, de 31 de julho de 2012, do Instituto Nacional de Metrologia, Qualidade e Tecnologia., ${ }^{5}, 12$

Na prática, na UAN nota-se a falta de padronização das capacidades volumétricas dos utensílios e dos equipamentos entre as empresas fornecedoras na linha industrial. ${ }^{13}$ Observa-se a falta de nomenclatura dos equipamentos nas UANs. Por exemplo: um carrinho - pode significar carro térmico, carro de transporte do tipo plataforma ou do tipo prateleira. ${ }^{13}$

Percebe-se a falta de consenso na literatura sobre as diferenças entre as descrições de equipamentos e utensílios utilizados nas UANs, uma vez que utensílios podem incluir maquinário temporário ou permanente e eletrodoméstico. ${ }^{13,16}$

Vale ressaltar que o caldeirão de alumínio (utensílio) avaliado no presente estudo não deve ser confundido com o caldeirão a vapor (equipamento) descrito na literatura, por vezes, como “caldeirão", uma vez que na prática a avaliação volumétrica entre eles são diferentes. . $^{2,17,18}$

Outro ponto a ser questionado é a falta de um manual de instruções durante a aquisição desses utensílios, a fim de oferecer garantia e maior segurança ao cliente sobre os possíveis aumentos nos índices da dissolução de alumínio durante o cozimento de alimentos, durante o preparo de alimentos ácidos e também durante a utilização de panelas de alumínio novas. ${ }^{3,19}$

\section{Conclusões}

Dessa forma, este estudo contribuiu para demonstrar que a capacidade volumétrica de caçarolas e caldeirões de alumínio analisados encontra-se em concordância com a legislação vigente e com os valores volumétricos descritos pelos fabricantes.

Entretanto, ao se considerar o valor percentual médio entre as variações da capacidade volumétrica das diferentes designações das caçarolas descritas na NBR: 14630, da Associação Brasileira de Normas Técnicas (2008), observou-se variação média percentual de 40\%. Dado preocupante, uma vez que tal valor percentual possui respaldo da Norma regulamentadora, no entanto, foram considerados expressivos pelos autores da presente pesquisa.

Ressalta-se a importância do tema aqui discutido, e considerando as variações permitidas pela NBR: 14630, da Associação Brasileira de Normas Técnicas (2008), quanto à capacidade volumétrica de caçarolas e caldeirões, sugere-se:

Maior cuidado na utilização desses utensílios durante a elaboração de preparações culinárias, devido às variações volumétricas observadas e permitidas por essa legislação. ${ }^{12}$ 
Reformulação da Norma Brasileira ${ }^{12}$ sobre as recomendações de valores máximos e mínimos de capacidade volumétrica, para as designações de caçarolas e caldeirões da linha doméstica e industrial, levando em conta variações volumétricas não superiores a $20 \%$. E acesso gratuito à Norma pela população brasileira.

Foi considerada limitação do presente estudo a não avaliação do diâmetro nominal e do nível de impureza (chumbo, arsênio, cádmio, mercúrio e cobre) das partes metálicas das caçarolas e caldeirões de alumínio, no entanto, devido à relevância do assunto, salienta-se a importância de novos estudos a fim de se avaliar o percentual de conformidade do diâmetro nominal e os níveis de impureza desses utensílios, entre os valores descritos pelos fabricantes, valores encontrados e concordância com os valores da legislação vigente..$^{5,11,12}$

\section{Agradecimentos}

Ao Programa Santander de Bolsa à Educação, concedendo uma bolsa de estudo a um dos pesquisadores.

\section{Referências}

1. Cascudo LC. História da alimentação no Brasil. 2. ed. São Paulo: Universidade de São Paulo; 1983. $268 \mathrm{p}$.

2. Campos VMC. Dossiê técnico. Fabricação de panelas de alumínio. Belo Horizonte: Fundação Centro Tecnológico de Minas Gerais - CETEC; 2007.20 p. Disponível em: http://sbrt.ibict.br/dossie-tecnico/ downloadsDT/MjE4

3. Bakirdere S, Gunes MY. Contamination of aluminium from cooking utensils and yogurt containers. Bull Environ Contam Toxicol. 2003; 70:437-442.

4. Quintaes KD, Farfan JA, Tomazini FM, Morgano MA. Migração de minerais de panelas brasileiras de aço inoxidável, ferro fundido e pedra -sabão (esteatito) para preparações culinárias. ALAN 2007; 56(3):397-402.

5. Brasil. Ministério da Saúde. Instituto Nacional de Metrologia, Qualidade e Tecnologia (INMETRO). Portaria no 398 de 31 de julho de 2012. Dispõe sobre o Regulamento Técnico da Qualidade para Panelas Metálicas. Diário Oficial da União 01 ago. 2012.

6. WeidenhamerJD, Corbin RW, Kuepouo G, Kobunski PA, Gottesfeld P. Lead exposure from aluminum cookware in Cameroon. Sci Total Environ. 2014; 47:339-496.

7. Houaiss A. Dicionário Houaiss da língua portuguesa. Rio de Janeiro: Objetiva; 2001.

8. Ferreira A. Dicionário Aurélio da língua portuguesa. 5 ed. Rio de Janeiro: Positivo; 2010.

9. Santos VFN, Alves MAA. Unidade de Alimentação e Nutrição no Brasil: conhecendo o perfil de seus pesquisadores. Rev Cient Linkania Master 2014; 9(5):84-99. 
10. Silva LC, Santos DB, São José JFB, Silva EMM. Boas práticas na manipulação de alimentos em Unidades de Alimentação e Nutrição. Demetra 2015; 10(4):797-820.

11. Brasil. Ministério da Saúde. Instituto Nacional de Metrologia, Qualidade e Tecnologia (INMETRO). Portaria n. ${ }^{\circ} 408$ de 21 de agosto de 2015. Dispõe sobre Adequação do Regulamento Técnico da Qualidade e dos Requisitos de Avaliação da Conformidade para Panelas Metálicas. Diário Oficial da União 24 ago. 2015.

12. Associação Brasileira de Normas Técnicas. Norma Brasileira: 14630. Dispõe sobre utensílios domésticos metálicos para uso em forno e fogão. Rio de Janeiro: ABNT; 2008.

13. Mezomo IFB. Os serviços de alimentação planejamento e administração. 6. ed. São Paulo: Manole; 2015.

14. Hochman B, Nahas FX, Oliveira Filho RS, Ferreira LM. Desenho de pesquisa. Acta Cirúrgica Brasileira 2005; 20(5):2-9.

15. Abreu ES, Spinelli MGN, Pinto AMS. Gestão de Unidades de Alimentação e Nutrição: um modo de fazer. 5. ed. São Paulo: Metha; 2013. 125 p.

16. Descritores em Ciências da Saúde. DECS. Biblioteca Virtual de Saúde. Disponível em: www.decs.bvs.br

17. Teixeira S, Milet Z, Carvalho J, Biscontini TM. Administração aplicada ás Unidades de Alimentação e Nutrição. São Paulo: Atheneu; 2007. 107 p.

18. Silva Filho ARA. Manual básico para planejamento e projeto de restaurantes e cozinhas industriais. São Paulo: Varela; 2001. 65 p.

19. Dantas ST, Saron ES, Dantas FBH, Yamashita M, Kiyataka M. Determinação da dissolução de alumínio durante o cozimento de alimentos em panelas de alumínio. Ciênc Tecnol Aliment. 2007; 27(2):291-297. 